\title{
PENGARUH CITRA MEREK, KUALITAS LAYANAN DAN PRODUK TERHADAP LOYALITAS NASABAH PT. BANK MAYBANK Tbk, CAPEM CITRA RAYA CIKUPA
}

\author{
Imas Sukaesih \\ Fakultas Ekonomi dan Bisnis \\ Universitas Islam Syekh-Yusuf \\ isukaesih@unis.ac.id \\ DOI: https://doi.org/10.33592/jeb.v26i1.733
}

Abstract

This study aims to identify and analyze (1) the extent of the influence of brand image pasial on customer loyalty, (2) the extent of the influence of the partial service quality on customer loyalty, (3) the extent of the effect of partial products on customer loyalty (4) the extent of the influence of image brand, quality of service and products simultaneously on customer loyalty PT Bank Mega Tbk, .

The research method used is quantitative research. The study population was a customer of Bank Mega branch Pondok Indah. While the sample of 150 respondents. Data collection instruments are arranged in a questionnaire using Likert scale. Data analysis was performed at a significance level of $95 \%$.

There Variables Influence Brand Image, Quality of Services and Products Collectively Customer Loyalty In PT Bank Mega. The correlation coefficient was 0.659. Coefficient of determination of $96.9 \%$ variance that occurs in customer loyalty can be explained by Brand Image, Kualita Services and Products. F test Generates Fhitung at 37.263> $F=3.91$ with a regression equation: $y=-2.228+0.288$ $0.216 X 1+X 2+X 3$ So 0,407 variables Brand Image, Quality of Services and Products Together effect on customer loyalty PT. Bank Mega. The conclusion of this study there are significant Brand Image, Quality Services and Products Partial or Together for Customer Loyalty PT. Bank Maybank Capem Citra Raya Cikupa Tangerang

Keywords: Brand Image, Service Quality, Products, Customer Loyalty

\begin{abstract}
Abstrak
Penelitian ini bertujuan untuk mengetahui dan menganalisis (1) sejauh mana pengaruh citra merek secara pasial terhadap loyalitas nasabah, (2) sejauh mana pengaruh kualitas layanan secara parsial terhadap loyalitas nasabah, (3) sejauh mana pengaruh produk secara parsial terhadap loyalitas nasabah (4)sejauh mana pengaruh citra merek, kualitas layanan dan produk secara simultan terhadap loyalitas nasabah PT Bank Maybank Tbk,.

Metode Penelitian yang digunakan adalah penelitian kuantitatif. Populasi penelitian ini adalah nasabah Bank Mega Cabang Pondok Indah. Sedangkan sampel penelitian sebesar 150 responden. Instrumen pengumpulan data disusun dalam angket yang menggunakan skala Likert. Analisis data dilakukan pada taraf signifikansi $95 \%$.

Terdapat Pengaruh Variabel Citra Merek, Kualitas Layanan dan Produk Secara Bersama Terhadap Loyalitas Nasabah Pada PT Bank Maybank.. Koefisien korelasinya adalah sebesar 0,659. Koefisien determinasi sebesar 96,9\% variansi yang terjadi pada loyalitas nasabah dapat dijelaskan oleh Citra Merek, Kualita Layanan, dan Produk. Uji $F$ Menghasilkan $F_{\text {hitung }}$ sebesar 37,263 > F = 3,91 dengan persamaan regresi : $\hat{Y}=-2,228+0,288 X_{1}+0,216 X_{2}+0,407 X_{3}$ Sehingga variabel Citra Merek, Kualitas Layanan dan Produk Secara bersama berpengaruh terhadap loyalitas nasabah PT. Bank Maybank. Kesimpulan dari penelitian ini terdapat pengaruh Citra Merek, Kualitas Layanan dan Produk Secara Parsial Maupun Bersama terhadap Loyalitas Nasabah PT. Bank Maybank. Capem Citra Raya Cikupa Tangerang.
\end{abstract}

Kata Kunci : Citra Merek, Kualitas Layanan, Produk, Loyalitas Nasabah 


\section{A. Pendahuluan}

Banyaknya persaingan produk sejenis mendorong perusahaan melakukan langkah - langkah yang tepat agar dapat bertahan ditengah persaingan yang ketat untuk tetap mempertahankan nasabahnya. Membina hubungan baik dengan nasabah adalah sebagian layanan yang wajib diberikan, karena hubungan baik akan menentukan nilai dan kelangsungan masa depan perusahaan.

Masyarakat sebagai konsumen atau pasar yang dituju oleh industri perbankan memiliki berbagai pertimbangan dalam memilih usaha jasa perbankan yang akan digunakannya, hal tersebut dapat dilihat dari faktor tingkat bunga yang ditawarkan oleh perbankan kepada masyarakat, tingkat kenyamanan yang dirasakan oleh masyarakat dalam hal penyimpanan uang pada bank tersebut, juga mengenai kemudahan dalam memperoleh pinjaman.

Faktor-faktor tersebut yang menjadi dasar pertimbangan masyarakat untuk memilih jasa perbankan, baik secara langsung maupun tidak langsung dapat membentuk loyalitas pada diri masyarakat akan bank yang dijadikan sebagai pilihan yang dipercayainya. Dengan ketatnya persaingan dimana jumlah pesaing yang begitu banyak, dimana antara suatu bank dengan bank yang lain saling menawarkan keunggulan produknya, menunjukan kualitas pelayanannya, dan terus memperkuat citra merek adanya nasabah yang berpindah ke bank lain Hal ini yang membuat PT. Bank Maybank harus membuat langkah dimana perusahaan berusaha mempertahankan dan memperbaiki Citra Merek ,memberikan pelayanan dan produk yang baik demi menambah jumlah nasabah dan mempertahankan nasabah yang sudah ada.

\section{Kerangka Pemikiran}

\section{Gambar 1}

Model Penelitian

$\underline{\text { Variabel Bebas }}$

$\underline{\text { Variabel Terikat }}$

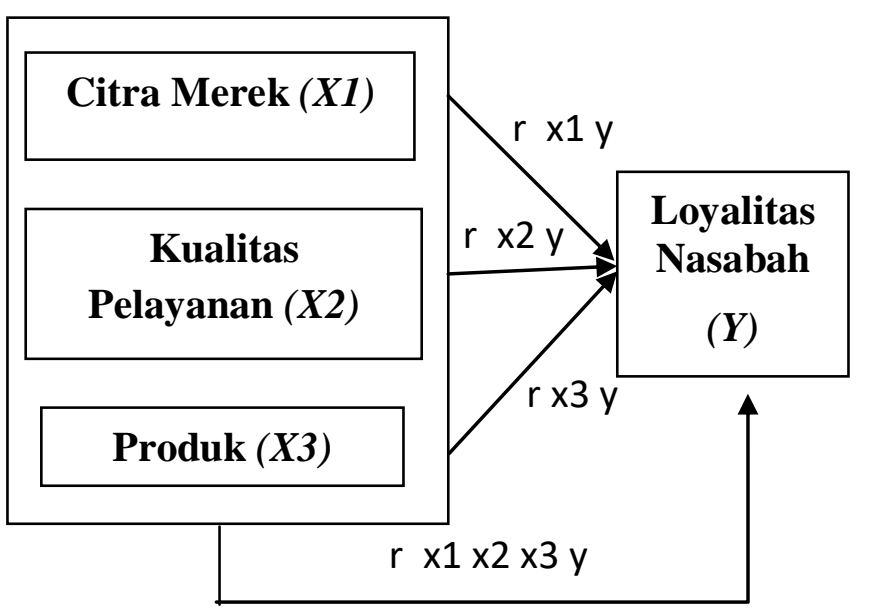

\section{B. Metode Penelitian}

Penelitian ini menggunakan metode penelitian deskriptif survey. Metode penelitian deskriptif adalah suatu metode dalam meneliti status kelompok manusia, obyek, suatu set kondisi, suatu sistem 
pemikiran, ataupun peristiwa yang sedang dialami oleh individu atau kelompok. Tujuannya adalah untuk membuat deskripsi, gambaran, atau lukisan secara sistematis, faktual dan akurat mengenai karakteristik, fakta-fakta, sifat-sifat serta hubungan antar fenomena yang diselidiki.

\section{Populasi dan Sampel}

Adapun survey dilakukan dengan menyebarkan angket kepada responden. Angket yang telah dibuat kemudian disebar kepada sejumlah sampel yang menjadi obyek penelitian. Obyek yang dijadikan dasar pemilihan populasi pada penelitian ini adalah nasabah PT Bank Maybank. Sampel adalah sebagian atau populasi yang diteliti.

Menurut Cochrane (2018 :125) Populasi disampelkan sama dengan populasi yang memuat informasi yang dibutuhkan (populasi sasaran).

Sampel penelitian diambil sebanyak 150 nasabah PT. Bank Maybank. Penentuan sampel ini sesuai dengan pendapat Roscoe dalam Sugiyono (2019: 132) menyatakan dan memberikan saran tentang ukuran sampel untuk penelitian yaitu "ukuran sampel yang layak dalam penelitian adalah antara minimal 30 sampai dengan 500".
Sesuai dengan pendapat tersebut sebagai rujukannya, dan didukung oleh adanya keterbatasan waktu dan kesibukan penulis, maka sampel penelitian diambil sebesar 150 nasabah. Dimana nasabah tersebut memiliki kontribusi terhadap cabang.

\section{Hasil Penelitian dan Pembahasan Statistik Deskriptif}

\section{Deskripsi Data Responden}

Kuesioner yang disebar sejumlah 150 kepada responden. Berdasarkan data kuesioner yang disebar maka deskripsi responden pada penelitian ini adalah sebagai berikut:

\section{Tabel 1}

Deskripsi Data Responden Berdasarkan Jenis Kelamin

\begin{tabular}{|c|c|c|c|}
\hline No & Jenis Kelamin & Jumlah & Prosentase \\
\hline 1. & Pria & 87 & $58 \%$ \\
\hline 2. & Wanita & 63 & $42 \%$ \\
\hline \multicolumn{2}{|c|}{ Jumlah } & 150 & $100.00 \%$ \\
\hline
\end{tabular}

Sumber : Data Primer Diolah

Dari tabel di atas, dapat dilihat berdasarkan jenis kelamin responden terlihat responden yang berjenis kelamin pria lebih banyak dengan jumlah 87 responden atau sebesar 58\% dibandingkan dengan jumlah responden berjenis kelamin wanita yaitu 63 orang atau $42 \%$. 


\section{Deskripsi Responden Berdasarkan Usia}

Usia responden pada penelitian ini adalah sebagai berikut :

\section{Tabel 2}

Deskripsi Data Responden Berdasarkan Usia

\begin{tabular}{|c|c|c|c|}
\hline No & Usia & Jumlah & Prosentase \\
\hline 1 & $<20$ Tahun & 2 & $1 \%$ \\
\hline 2 & $20-30$ Tahun & 16 & $11 \%$ \\
\hline 3 & $31-40$ Tahun & 34 & $23 \%$ \\
\hline 4 & $41-50$ Tahun & 56 & $37 \%$ \\
\hline 5 & $>50$ Tahun & 42 & $28 \%$ \\
\hline \multicolumn{2}{|c|}{ Jumlah } & 150 & $100 \%$ \\
\hline
\end{tabular}

Sumber : Data Primer Diolah

Dari tabel di atas, dapat dilihat berdasarkan usia responden terlihat lebih banyak pada usia antara 41 tahun sampai dengan 50 tahun dengan jumlah 56 orang dengan prosentase sebesar $37 \%$. dan yang terendah berusia $<20$ tahun dengan 2 responden atau $1 \%$.

\section{Uji Normalitas Data}

Persyaratan analisis yang dimaksud adalah persyaratan lain yang harus dipenuhi agar analisis regresi dapat dilakukan, baik untuk keperluan prediksi maupun untuk keperluan pengujian hipotesis. Kegiatan ini dilakukan melalui uji normalitas data.

\section{Tabel 3}

\section{Uji Normalitas Data}

\begin{tabular}{|c|c|c|c|c|c|}
\hline \multicolumn{6}{|c|}{ One-Sample Kolmogorov-Smirnov Test } \\
\hline & & Citra & Kualitas & Produk & Loyalitas \\
\hline \multirow{3}{*}{$\begin{array}{l}\text { N } \\
\text { Normal Parameters, b }\end{array}$} & & 150 & 150 & 150 & 150 \\
\hline & Mean & 78,9600 & 79,8800 & 67,0867 & 65,0733 \\
\hline & Std. Deviation & 5,21727 & 3,52730 & 3,24593 & 4,36904 \\
\hline \multirow{3}{*}{$\begin{array}{l}\text { Most Extreme } \\
\text { Differences }\end{array}$} & Absolute & 099 &, 081 & 083 & 096 \\
\hline & Positive & 081 & 081 & 063 & 096 \\
\hline & Negative &,- 099 &,- 064 &,- 083 & -096 \\
\hline \multicolumn{2}{|l|}{ Kolmogorov-Smirnov Z } & 1,207 &, 987 & 1,013 & 1,179 \\
\hline \multicolumn{2}{|l|}{ Asymp. Sig. (2-tailed) } & 108 & 284 &, 257 & 124 \\
\hline
\end{tabular}

Dari tabel diatas dapat dilihat hasil perhitungan Asymp.sig.(2-tailed) variabel citra sebesar 0,108 maka data $X_{1}$ berasal dari data yang berdistribusi normal. Hasil perhitungan Asymp.sig.(2-tailed) variabel kualitas layanan sebesar 0,284 maka data $\mathrm{X}_{2}$ berasal dari data yang berdistribusi normal. Hasil perhitungan Asymp.sig.(2tailed) variabel data produk sebesar 0,257 maka data $X_{3}$ berasal dari data yang berdistribusi normal. Hasil perhitungan Asymp.sig.(2-tailed) variabel loyalitas sebesar 0,124 maka data $\mathrm{X}_{4}$ berasal dari data yang berdistribusi normal.

\section{Uji Multikolinearitas}

Uji multikolinearitas merupakan salah satu dari uji asumsi klasik supaya penyusunan model regresi mencapai suatu taksiran yang memiliki sifat BLUE (Best Linear Unbiased Estimator). Jika asumsi klasik tidak terpenuhi, berarti bahwa variabel independen bukan merupakan prediktor yang baik bagi variable dependen. 
Multikolinearitas (kolinearitas ganda) berarti adanya hubungan linear yang sempurna di antara variabel-variabel bebas dalam model regresi korelasi yang kuat antar variabel bebas.

Gejala multikolinearitas dapat dilihat atau dideteksi dari nilai tolerance atau nilai VIF (Variance Inflation Factor). Kedua ukuran ini menunjukkan variabel bebas yang dijelaskan oleh variabel bebas lainnya. Tolerance mengukur variabilitas variabel bebas yang terpilih yang tidak dapat dijelaskan oleh variabel bebas lainnya. Jadi nilai tolerance yang rendah sama dengan nilai VIF yang tinggi ( Karena VIF = 1/tolerance ), yang menunjukkan adanya kolinieritas yang tinggi. Tidak adanya gejala multikolinearitas dapat dilihat dari nilai tolerance yang lebih dari 0.1 atau VIF yang kurang dari 10. Pengujian multikolinearitas pada penelitian ini memberikan hasil seperti ditunjukkan dalam tabel berikut ini :

\section{Tabel 4} Uji Multikolinearitas Coefficients

\begin{tabular}{|c|c|c|c|c|c|c|c|}
\hline \multirow[b]{2}{*}{ |Model } & \multicolumn{3}{|c|}{\begin{tabular}{c|c} 
Unstandadizized & Standadrized \\
Coefficients & Coefficients \\
\end{tabular}} & \multirow[b]{2}{*}{1} & \multirow[b]{2}{*}{ Sig. } & \multicolumn{2}{|c|}{ Collinearity Statistics } \\
\hline & $B$ & Stod. Erro & Beta & & & Tolerance & VF \\
\hline $1 \quad$ (Constant & .2228 & 6,902 & & .323 &, 747 & & \\
\hline Citra &, 288 &, 060 & 344 & 4,820 &, 000 &, 762 & 1,313 \\
\hline Kualitias & 216 & 091 & , 175 & 2,382 & ,018 &, 722 & 1,384 \\
\hline Produk &, 407 &, 103 & 302 & 3,935 &, 000 & 6,658 & 1,520 \\
\hline
\end{tabular}

Nilai toleransi tidak ada yang dibawah 0.1 dan nilai vif tidak ada yang lebih dari 10 maka data dikatakan bebas dari multikolinearitas dan tidak ada hubungan antar variabel independen

\section{Uji Heterokesdastisitas}

Uji heteroskedastisitas dilakukan dengan melihat grafik scatter. Apabila terlihat titik-titik residual menyebar secara acak baik diatas maupun dibawah angka nol pada sumbu $Y$ dan titik-titknya menyebar tidak menyerupai bentuk tertentu, maka menggambarkan bahwa tidak terjadi penyimpangan asumsi klasik heteroskedastisitas. Berdasarkan hasil analisis hasil uji heteroskedastisitas dapat dilihat pada gambar berikut: 


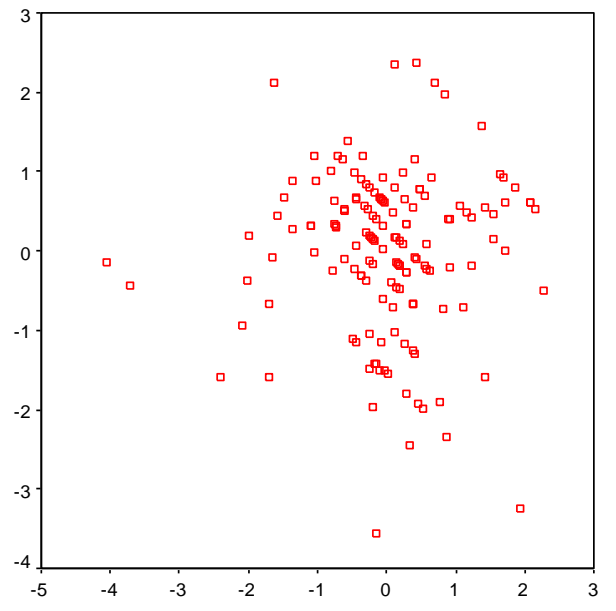

Gambar 2 grafik scatter

\section{Uji Autokorelasi}

Digunakan untuk mendeteksi adanya korelasi internal diantara anggota-anggota dari serangkaian pengamatan. Terjadinya autokorelasi atau tidak, dapat dilihat pada nilai d (Durbin Watson) dalam analisis regresi linear berganda.

\section{Tabel 5}

\section{Uji Durbin Watson}

\begin{tabular}{|l|l|}
\hline Jika & Keputusan \\
\hline $0<\mathrm{d}<\mathrm{dl}$ & Ada auto korelasi positif \\
\hline $\mathrm{d} l \leq \mathrm{d} \leq \mathrm{du}$ & Tidak ada keputusan \\
\hline $4-\mathrm{dl}<\mathrm{d}<4$ & Ada auto korelasi negative \\
\hline $4-\mathrm{du} \leq \mathrm{d} \leq 4-\mathrm{dl}$ & Tidak ada keputusan \\
\hline $\mathrm{du}<\mathrm{d}<4-\mathrm{du}$ & $\begin{array}{l}\text { Tidak ada autokorelasi } \\
\text { positif atau negative }\end{array}$ \\
\hline
\end{tabular}

Sumber : Ghozali (2018: 112)
Tabel 6

Model Summary
\begin{tabular}{|l|r|r|r|r|r|}
\hline Model & \multicolumn{1}{|c|}{ R } & R Square & $\begin{array}{l}\text { Adjusted } \\
\text { R Square }\end{array}$ & $\begin{array}{r}\text { Std. Error of } \\
\text { the Estimate }\end{array}$ & $\begin{array}{r}\text { Durbin- } \\
\text { Watson }\end{array}$ \\
\hline 1 &, $659^{2}$ &, 434 &, 422 & 3,32160 & 1,852 \\
\hline
\end{tabular}
a. Predictors: (Constant), Produk, Citra, Kualitas
b. Dependent Variable: Loyalitas

Nilai durbin watson tabel sebesar 1,852, berada di antara dU dan 4-dU, seperti berikut ini: $1,7708<1,852<$ 2,2292 Maka dikatakan tidak terjadi autokorelasi.

\section{Uji Parsial / Uji t}

Untuk melihat pengaruh variabel bebas secara parsial terhadap variabel terikat, pembuktian dilakukan dengan uji t, yaitu dengan membandingkan antara nilai $t$ hitung masing-masing variabel bebas dengan $\mathrm{t}$ tabel (nilai kritis dengan tingkat signifikansi 5\%). Jika $\mathrm{t}$ hitung variabel bebas, lebih kecil daripada $\mathrm{t}$ tabel, atau $\mathrm{t}$ hitung (-) lebih besar daripada $t_{\text {tabel }}$ negatif, maka berarti bahwa variabel bebas tidak berpengaruh terhadap variabel terikat. Sebaliknya jika $t_{\text {hitung }}$ variabel bebas lebih besar daripada $\mathrm{t}$ tabel atau $\mathrm{t}$ hitung lebih kecil dari $\mathrm{t}$ tabel (-), maka berarti bahwa variabel bebas berpengaruh terhadap variabel terikat.

Berdasarkan hasil analisa diperoleh harga $t_{\text {hitung }}$ sebesar 21,750 . Untuk jelasnya dapat dilihat pada tabel berikut: 
Tabel 7

Uji Parsial / Uji t

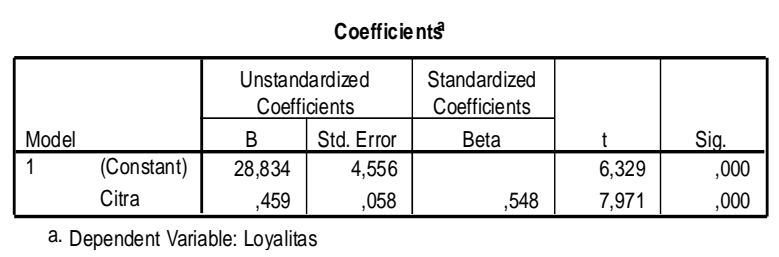

Berdasarkan hasil analisa diperoleh harga $t_{\text {hitung }}$ sebesar 7,971 lebih tinggi dari $t$ tabel $(\mathrm{n}=150 ; \alpha=0,05)=1,975$. Karena $\mathrm{t}_{\text {hitung }}\left(\mathrm{t}_{\mathrm{h}}=7,971>\mathrm{t}_{\mathrm{t}}=1,975\right)$, maka terdapat pengaruh antara citra merek terhadap loyalitas nasabah.

\section{Uji Simultan / Uji F}

Uji keberartian dengan menggunakan uji $\mathrm{F}$ yaitu sebesar $F_{\text {hitung }}=37,263$. Untuk lebih jelasnya dapat dilihat pada tabel berikut:

\section{Tabel 8}

\section{Uji Simultan / Uji F}

\begin{tabular}{|c|c|c|c|c|c|c|}
\hline \multicolumn{7}{|c|}{ ANOV A } \\
\hline Model & & $\begin{array}{l}\text { Sum of } \\
\text { Squares }\end{array}$ & df & Mean Square & $\mathrm{F}$ & Sig. \\
\hline \multirow[t]{3}{*}{1} & Regression & 1233,373 & 3 & 411,124 & 37,263 & $.000^{2}$ \\
\hline & Residual & 1610,820 & 146 & 11,033 & & \\
\hline & Total & 2844,193 & 149 & & & \\
\hline
\end{tabular}

Karena $(\mathrm{Fh}=37,263>\mathrm{Ft}=3,91)$, maka $\mathrm{H}_{\mathrm{o}}$ ditolak yang berarti $\mathrm{H}_{\mathrm{a}}$ diterima sehingga dengan demikian variabel citra, kualitas dan produk secara serentak (simultan) berpengaruh terhadap loyalitas.

\section{Koefisien Korelasi Ganda}

Perhitungan korelasi ganda antara variabel $X_{1}, X_{2}$ dan variabel $X_{3}$ dengan variabel $\mathrm{Y}$ menghasilkan koefisien korelasi sebesar $\mathrm{R}=0,659$. Untuk jelasnya dapat dilihat pada tabel berikut:

\section{Tabel 9}

\section{Uji Korelasi Berganda}

Model Summary
\begin{tabular}{|l|c|r|r|r|c|}
\hline Model & R & R Square & $\begin{array}{c}\text { Adjusted } \\
\text { R Square }\end{array}$ & $\begin{array}{c}\text { Std. Error of } \\
\text { the Estimate }\end{array}$ & $\begin{array}{c}\text { Durbin-W } \\
\text { atson }\end{array}$ \\
\hline 1 &, $659^{\mathrm{a}}$ &, 434 &, 422 & 3,32160 & 1,852 \\
\hline
\end{tabular}
a. Predictors: (Constant), Produk, Citra, Kualitas
b. Dependent Variable: Loyalitas

Nilai ini mengandung arti bahwa citra merek, kualitas layanan dan produk memiliki hubungan yang Cukup Kuat dengan loyalitas.

\section{Koefisien Determinasi}

Koefisien determinasi sebesar $\mathrm{R}^{2}=$ $(0,659)^{2}=0,434$. Ini menunjukkan bahwa $43,4 \%$ dari variabel citra merek, kualitas layanan dan produk secara bersama-sama memberikan kontribusi sebesar 43,4\% terhadap loyalitas.

\section{Kesimpulan Dan Saran}

\section{Kesimpulan}

Dari hasil temuan penelitian, maka dapat diambil kesimpulan sebagai berikut :

1. Terdapat pengaruh positif Citra Merek secara parsial terhadap loyalitas nasabah.

2. Terdapat pengaruh positif Kualitas Layanan secara parsial terhadap loyaloitas nasabah.

3. Terdapat pengaruh positif Produk secara parsial terhadap loyalitas nasabah. 
4. Terdapat pengaruh positif Citra Merek, Kualitas Layanan, dan Produk Secara Simultan terhadap loyalitas nasabah.

\section{Saran}

Berdasarkan kesimpulan di atas, maka dapat diajukan beberapa saran sebagai berikut:

1. Berdasarkan hasil ana pada bab IV diketahui bahwa secara keseluruhan variabel bebas memiliki pengaruh yang positif terhadap loyalitas nasabah. Dalam hal citra merek, perusahaan harus senantiasa menjaga reputasi bank yanjg sudah baik di mata nasabah demi mempertahankan dan menembah jumlah nasabahnya, serta meningkatkan loyalitas nasabah yang sudah ada maupun yang baru bergabung

2. Dalam hal kualitas layanan, semua hal yang berkaitan dengan pelayanan yang diberikan kepada nasabah, hendaknya terus dipelihara oleh seluruh karyawan sikap mental yang baik, penampilan, pelayanan sepenuh hati dari gangguan pribadi, ekstern, dan organisasi yang dapat mempengaruhi kualitas layanan.

3. Dalam hal kualitas produk, perusahaan harus senantiasa melakukan riset produk - produk bank terbaru, melakukan evaluasi terhadap prouk yang sudah ada karena produk merupakan salah satu faktor yang penting bagi kelangsungan hidup perusahaan.

4. Loyalitas nasabah dipengaruhi oleh banyak faktor. Berdasarkan penelitian yang diperoleh adanya Citra Merek yang baik, Kualitas layanan yang baik, serta produk yang berkualitas yang dimiliki suatu bank mampu meningkatkan loyalitas nasabah. Oleh karena itu faktor Citra Merek, Kualitas Layanan, dan Produk hendaknya dapat dikaji lebih mendalam, karena terbukti faktor tersebut berpengaruh positif dan signifikan terhadap loyalitas nasabah.

\section{E. DAFTAR PUSTAKA}

Buchari, Alma.2004. Manajemen Pemasaran dan Pemasaran Jasa. Alfabeta. Bandung

Chan, Syafrudin.2003. Relationship Marketing.Gramedia Pustaka Utama. Jakarta

Cochran, W.G. 2018. Tekhnik Penarikan Sampel. Penerbit Universitas Indonesia. Jakarta

Ghozali, Imam. 2018. Aplikasi Analisis Multivariate Dengan Program SPSS. Badan Penerbit Universias Diponegoro. Semarang 
Griffin, Jill. 2003. Customer Loyalty : Menumbuhkan dan mempertahankan Kesetiaan Pelanggan, alih bahasa Kartini Yahya. Erlangga. Jakarta

Keller, Kevin Lane. 1993. Conceptualizing, Measuring and Managing Customer Based Brand Equity. Journal of Marketing and LogisticsVol. 20 Iss : 2,pp.139-155

Keller, Kevin Lane. 2008. Strategic Brand Management : Building, Measuring, and managing Brand Equity 3rd Edition. Upper Saddle River : Pearson Education, Inc

Kotler, Philip. 2001. Manajemen Pemasaran di Indonesia : Analisis, Perencanaan, Implementasi dan Pengendalian. Salemba Empat. Jakarta.
Kotler, Philip. 2016. Marketing Management 11th Edition. New Jersey : Prantice Hall

Kotler, Philip. 2016. Manajemen Pemasaran. Edisi 13. Erlangga . Jakarta.

Kasmir. 2004. Pemasaran Bank. Prenada Media . Jakarta.

Sulistyawati, Praba (2015)'Pengaruh Kualitas Produk dan Citra Merek Terhadap Keputusan Pembelian Laptop Merek Acer di Kota Semarang” Universitas Diponegoro Semarang

Sugiyono. 2019. Metode Penelitian Bisnis. Alfabeta. Bandung. 